\title{
Article
}

Mycosphere

Doi 10.5943/mycosphere/11/1/21

\section{Terrestriporiaceae fam. nov., a new family of Russulales (Basidiomycota)}

\author{
Wu F ${ }^{1 \#}$, Yuan $Y^{1 \#}$, Chen $J^{2}$, Cui BK ${ }^{1}$, Zhou $M^{1}$ and Dai YC ${ }^{1,3^{*}}$ \\ ${ }^{1}$ Institute of Microbiology, School of Ecology and Nature Conservation, Beijing Forestry University, Beijing 100083, \\ China \\ ${ }^{2}$ College of Landscape Architecture, Jiangsu Polytechnic College of Agriculture and Forestry, Zhenjiang 212400, China \\ ${ }^{3}$ Beijing Advanced Innovation Center for Tree Breeding by Molecular Design, Beijing Forestry University, Beijing \\ 100083, China
}

Wu F, Yuan Y, Chen JJ, Cui BK, Zhou M, Dai YC 2020 - Terrestriporiaceae fam. nov., a new family of Russulales (Basidiomycota). Mycosphere 11(1), 2755-2766, Doi 10.5943/mycosphere/11/1/21

\begin{abstract}
A new family of Russulales, Terrestriporiaceae fam. nov. is proposed based on the combination of molecular and morphological data, and it is typified by Terrestriporia gen. nov. The phylogenetic analyses inferred from the combined dataset of five genes, including ITS, nLSU, RPB1, RPB2 and TEF1, show that Terrestriporia alba sp. nov. forms a monophyletic lineage within Russulales. The Bayesian evolutionary analysis on two datasets of RPB1 and RPB2 sequences indicate an ancient divergence of the new family from Albatrellaceae during the Cretaceous (124.68 \pm 0.39 Mya). The new family is characterized by annual and resupinate basidioma, poroid hymenophore, a monomitic hyphal structure, and generative hyphae mostly simple septate, but occasionally having clamp connections, the presence of gloeoplerous hyphae and cystidioles, thin-walled, hyaline, smooth, amyloid and acyanophilous basidiospores.
\end{abstract}

Key words - phylogeny - polypore - taxonomy - wood-inhabiting fungi

\section{Introduction}

The Russulales Kreisel ex P.M. Kirk, P.F. Cannon \& J.C. David is a highly diverse group of Agaricomycetes including around 2000 described species in 83 genera and 13 families (Kirk et al. 2008, Chen et al. 2016, Hyde et al. 2017, Wang 2018, Caboňet al. 2019, Vidal et al. 2019). It contains not only the lamellate species like Russula Pers. and Lactarius Pers. (Herrera et al. 2018, Caboň et al. 2019), but also the poroid, hydnoid and corticioid representatives like Heterobasidion Bref., Hericium Pers. and Asterostroma Massee (Chen et al. 2015, Liu et al. 2017). Russulales is a very important group of basidiomycetes because of the ectomycorrhizal, saprobic and pathogenic species (Henkel et al. 2000, Chen et al. 2016). However, the phylogeny among many taxa in the order is not well demonstrated (Larsson et al. 2004, Chen et al. 2016, Liu et al. 2017, Leal-Dutra et al. 2018, Vizzini1 et al. 2018).

During a field trip to Malaysia, four samples were collected on soil in a tropical forest. These samples have resupinate basidiocarps with poroid hymenophore, and the ecology and macromorphology are similar to those of Byssoporia terrestris (DC.) M.J. Larsen \& Zak. After further laboratory examination we found these samples have thin-walled and amyloid basidiospores, while Byssoporia terrestris has thick-walled non-amyloid basidiospores. The multi-locus phylogenetic analysis on these samples and related taxa was carried out, the Malaysian samples form a 
monophyletic lineage within Russulales, and no existing family fits them, so we described a new species for these samples. A new genus and a new family are proposed for accommodating the new species. In addition, based on RPB1 and RPB2 sequences the Bayesian evolutionary analysis is carried out to indicate divergence time of the new family.

\section{Materials \& Methods}

\section{Morphological studies}

The studied specimens are deposited in the herbarium of the Institute of Microbiology, Beijing Forestry University (BJFC), Royal Botanic Gardens Victoria (MEL), and the private herbarium of Josef Vlasák (JV) which will be sent to National Museum Prague (PRM). Morphological descriptions are based on field notes and herbarium specimens. Microscopic analyses follow Song \& Cui (2017). In the description: $\mathrm{KOH}=5 \%$ potassium hydroxide, $\mathrm{CB}-=$ acyanophilous in Cotton Blue, IKI $-=$ neither amyloid nor dextrinoid in Melzer's reagent. The microscopical measurements and drawings were made from slide preparations stained with Cotton Blue, $\mathrm{L}=$ arithmetic average of all spore length, $\mathrm{W}=$ arithmetic average of all spore width, $\mathrm{Q}=\mathrm{L} / \mathrm{W}$ ratios, $\mathrm{n}=$ number of spores/measured from given number of specimens. Special color terms are cited from Anonymous (1969) and Petersen (1996).

\section{DNA extraction, PCR and sequencing}

A CTAB rapid plant genome extraction kit (Aidlab Biotechnologies, Beijing) was used to obtain PCR products from dried specimens, according to the manufacturer's instructions with some modifications (Chen et al. 2016). The DNA was amplified with the primers: ITS5 and ITS4 for ITS (White et al. 1990), LR0R and LR7 for nLSU (Vilgalys \& Hester 1990), RPB1-Af and RPB1-Cr for RPB1 (Matheny et al. 2002), bRPB2-6F and bRPB2-7R for RPB2 (Matheny 2005), and EF1-983F and EF1-1567R for TEF1 (Rehner 2001). The PCR procedure for ITS and TEF1 was as follows: initial denaturation at $95^{\circ} \mathrm{C}$ for $3 \mathrm{~min}$, followed by 35 cycles at $94^{\circ} \mathrm{C}$ for $40 \mathrm{~s}, 54^{\circ} \mathrm{C}$ for $45 \mathrm{~s}$ and $72^{\circ} \mathrm{C}$ for $1 \mathrm{~min}$, and a final extension of $72^{\circ} \mathrm{C}$ for $10 \mathrm{~min}$. The PCR procedure for nLSU was as follows: initial denaturation at $94^{\circ} \mathrm{C}$ for $1 \mathrm{~min}$, followed by 35 cycles at $94^{\circ} \mathrm{C}$ for $30 \mathrm{~s}, 50^{\circ} \mathrm{C}$ for $1 \mathrm{~min}$ and $72^{\circ} \mathrm{C}$ for $1.5 \mathrm{~min}$, and a final extension of $72^{\circ} \mathrm{C}$ for $10 \mathrm{~min}$. The PCR procedure for RPB1 and RPB2 included an initial denaturation at $94^{\circ} \mathrm{C}$ for $2 \mathrm{~min}$, followed by 10 cycles at $94^{\circ} \mathrm{C}$ for $40 \mathrm{~s}, 60^{\circ} \mathrm{C}$ for $40 \mathrm{~s}$ and $72^{\circ} \mathrm{C}$ for $2 \mathrm{~min}$, then followed by 37 cycles at $94^{\circ} \mathrm{C}$ for $45 \mathrm{~s}, 53-58^{\circ} \mathrm{C}$ for $1.5 \mathrm{~min}$ and $72^{\circ} \mathrm{C}$ for $2 \mathrm{~min}$, and a final extension of $72^{\circ} \mathrm{C}$ for $10 \mathrm{~min}$. The PCR products were purified and sequenced in Beijing Genomics Institute, China with the same primers.

\section{Phylogenetic analyses}

New sequences, deposited in GenBank (Table 1), were aligned with additional sequences retrieved from GenBank (Table 1) using BioEdit (Vilgalys \& Hester 1990) and ClustalX (Thompson et al. 1997). Calocera cornea (Batsch) Fr. and Dacryopinax spathularia (Schwein.) G.W. Martin were used as outgroups. Prior to phylogenetic analysis, ambiguous regions at the start and the end of the alignment were deleted and gaps were manually adjusted to optimize the alignment. The edited alignment was deposited at TreeBase (Treebase No. 25791).

Table 1 A list of species, specimens and GenBank accession number of sequences used in this study

\begin{tabular}{lllllll}
\hline Species & $\begin{array}{l}\text { Specimen } \\
\text { Number }\end{array}$ & ITS & LSU & RPB1 & RPB2 & TEF1 \\
\hline Albatrellus avellaneus & Dai20805 & - & - & MW290309 & MW290302 & - \\
Albatrellus avellaneus & Dai20806 & MW269672 & MW269684 & MW290310 & MW290303 & MW290319 \\
Albatrellus ellisii & PKSR12 & KJ411956 & & KJ411963 & KJ411971 & - \\
Albatrellus ovinus & PS11795 & MW269673 & MW269685 & - & MW290304 & MW290320 \\
\hline
\end{tabular}


Table 1 Continued.

\begin{tabular}{|c|c|c|c|c|c|c|}
\hline Species & $\begin{array}{l}\text { Specimen } \\
\text { Number }\end{array}$ & ITS & LSU & RPB1 & RPB2 & TEF1 \\
\hline $\begin{array}{l}\text { Aleurocystidiellum } \\
\text { disciforme }\end{array}$ & NH 13003 & AF506402 & AF506402 & - & - & - \\
\hline $\begin{array}{l}\text { Aleurocystidiellum } \\
\text { subcruentatum }\end{array}$ & He2886 & KU559341 & KU574847 & - & - & KU992720 \\
\hline $\begin{array}{l}\text { Aleurodiscus } \\
\text { bambusinus }\end{array}$ & He4361 & KY706207 & KY706219 & - & - & LC430911 \\
\hline $\begin{array}{l}\text { Aleurodiscus } \\
\text { wakefieldiae }\end{array}$ & $\mathrm{He} 2580$ & KU559353 & KU574841 & KX577720 & KX577723 & KU992710 \\
\hline $\begin{array}{l}\text { Amylostereum } \\
\text { laevigatum }\end{array}$ & olrim409 & AY781246 & AF287843 & - & AY218469 & - \\
\hline Amylostereumchailletii & B1387 & KM821143 & - & - & KM882973 & KM981422 \\
\hline Auricularia tibetica & Cui12267 & KT152106 & KT152122 & MW290311 & KT152139 & MW290321 \\
\hline Auriscalpium sp. & HKAS86980 & KY485962 & KY485989 & - & KY495306 & - \\
\hline Auriscalpium vulgare & HKAS93484 & MK211170 & KY485984 & - & KY495319 & KY474614 \\
\hline Boletus edulis & HMJAU4637 & JN563894 & KF112455 & KF112586 & KF112704 & KF112202 \\
\hline Bondarzewia berkeleyi & Dai 12759 & KJ583202 & KJ583216 & KX066152 & KX066162 & KX066138 \\
\hline Bondarzewia dickinsii & Dai 13413 & KJ583210 & KJ583224 & KX066151 & KX066161 & KX066137 \\
\hline $\begin{array}{l}\text { Bondarzewia } \\
\text { occidentalis }\end{array}$ & HHB 14803 & KM243329 & KM243332 & KX066156 & KX066163 & KX066142 \\
\hline $\begin{array}{l}\text { Bondarzewia } \\
\text { podocarpi }\end{array}$ & Cui 6380 & KJ583206 & KJ583220 & KX577718 & KX577721 & KX252745 \\
\hline Bondarzewia tibetica & Yu 56 & KT693203 & KT693205 & KX066158 & KX066165 & KX066148 \\
\hline Byssoporia terrestris & Hjm18172 & DQ389664 & DQ389664 & - & - & - \\
\hline Calocera cornea & AFTOL-ID 438 & AY789083 & AY701526 & AY857980 & AY536286 & AY881019 \\
\hline $\begin{array}{l}\text { Dacryopinax } \\
\text { spathularia }\end{array}$ & AFTOL-ID 454 & AY854070 & AY701525 & AY857981 & AY786054 & AY881020 \\
\hline $\begin{array}{l}\text { Echinodontium } \\
\text { tinctorium }\end{array}$ & AFTOL-ID 455 & AY854088 & AF393056 & AY864882 & AY218482 & AY885157 \\
\hline Exidia glandulosa & Wu265 & MN850376 & MN850356 & MW290312 & MN819812 & MN819834 \\
\hline Fomitiporia hartigii & Dai 11766 & KT203287 & KT203308 & KJ651628 & KJ651721 & - \\
\hline $\begin{array}{l}\text { Fomitiporia } \\
\text { mediterranea }\end{array}$ & AFTOL-ID 688 & AY854080 & AY684157 & AY864869 & AY803748 & AY885149 \\
\hline $\begin{array}{l}\text { Gloeophyllum } \\
\text { sepiarium }\end{array}$ & $\begin{array}{l}\text { CFMR Wilcox- } \\
\text { 3BB }\end{array}$ & NR_119869 & NG_060630 & - & HM536109 & HM536110 \\
\hline Gloeophyllum trabeum & isolate 1320 & HM536094 & HM536067 & - & HM536112 & HM536113 \\
\hline $\begin{array}{l}\text { Heterobasidion } \\
\text { annosum }\end{array}$ & $06129 / 6$ & KJ583211 & KJ583225 & KF033133 & KF006499 & KX252741 \\
\hline $\begin{array}{l}\text { Heterobasidion } \\
\text { parviporum }\end{array}$ & voucher 091605 & KJ651503 & KJ651561 & KJ651657 & KJ651750 & KX252742 \\
\hline Lactarius crocatus & KVP08034 & HQ318243 & HQ318151 & JN389145 & HQ328888 & - \\
\hline Lactarius deceptivus & AFTOL-ID 682 & AY854089 & AY631899 & AY864883 & AY803749 & AY885158 \\
\hline Lactarius sulphosmus & HMAS 276808 & NR_160503 & LT602948 & KX442536 & KX442559 & KX442513 \\
\hline Lactifluus sp. & HMAS 276798 & LT602968 & LT602945 & KX442533 & KX442556 & KX442510 \\
\hline Malassezia globosa & CBS 7966 & & & KF706493 & KF706518 & \\
\hline Marasmius rotula & $\begin{array}{l}\text { AFTOL-ID } \\
1505\end{array}$ & - & - & DQ447922 & DQ474118 & - \\
\hline Mycena amabilissima & $\begin{array}{l}\text { AFTOL-ID } \\
1686\end{array}$ & - & - & DQ447926 & DQ474121 & - \\
\hline Mycena aurantiidisca & $\begin{array}{l}\text { AFTOL-ID } \\
1685\end{array}$ & - & - & DQ447927 & DQ474122 & - \\
\hline Neurospora crassa & OR74A & & & XM959004 & AF107789 & \\
\hline Peniophora nuda & AFTOL-ID 660 & DQ411533 & - & - & DQ408129 & DQ435788 \\
\hline
\end{tabular}


Table 1 Continued.

\begin{tabular}{|c|c|c|c|c|c|c|}
\hline Species & $\begin{array}{l}\text { Specimen } \\
\text { Number } \\
\end{array}$ & ITS & LSU & RPB1 & RPB2 & TEF1 \\
\hline $\begin{array}{l}\text { Perplexostereum } \\
\text { endocrocinum }\end{array}$ & Dai15998 & KY172899 & KY172915 & - & - & - \\
\hline Phylloporia gutta & Dai16070 & MH151183 & MH165863 & MW290313 & MH161215 & MH167423 \\
\hline Picipes tibeticus & Cui12215 & KU189755 & KX196787 & KU189879 & KU189975 & KU189902 \\
\hline Polyporus squamosus & Cui10595 & KU189778 & KU189809 & KU189892 & KU189988 & KU189925 \\
\hline $\begin{array}{l}\text { Pseudowrightoporia } \\
\text { japonica }\end{array}$ & Dai12086 & KJ513293 & KM107883 & KX577719 & KX577722 & - \\
\hline Russula blennia & 569/BB08.066 & MH545687 & KU237556 & KU237701 & KU237842 & KU237987 \\
\hline Russula pseudociliata & 545/BB08.061 & MH545688 & KU237537 & KU237686 & KU237823 & KU237967 \\
\hline Serpula lacrymans & REG 383 & - & - & GU187485 & GU187809 & - \\
\hline Rhizopus stolonifer & AFTOL-ID 632 & & & $\begin{array}{l}\text { AFTOL } \\
\text { database }\end{array}$ & $\begin{array}{l}\text { AFTOL } \\
\text { database }\end{array}$ & \\
\hline $\begin{array}{l}\text { Schizosaccharomyces } \\
\text { pombe }\end{array}$ & $972 \mathrm{~h}$ & & & NM001021568 & $\begin{array}{l}\text { NM0010184 } \\
98\end{array}$ & \\
\hline Stereum hirsutum & AFTOL-ID 492 & AY854063 & - & AY864885 & AY218520 & AY885159 \\
\hline Suillus pictus & AFTOL-ID 717 & - & - & AY858965 & AY786066 & - \\
\hline Terrestriporia alba & Dai 18546 & MT068558 & MT068562 & MW290314 & MW290305 & MW290322 \\
\hline Terrestriporia alba & Dai 18547 & MT068559 & MT068563 & MW290315 & MW290306 & MW290323 \\
\hline Terrestriporia alba & Dai 18548 & MT068560 & MT068564 & MW290316 & MW290307 & MW290324 \\
\hline Terrestriporia alba & Dai 18556 & MT068561 & MT068565 & MW290317 & MW290308 & MW290325 \\
\hline Trametes suaveolens & Cui10697 & KC848280 & KC848365 & KX880839 & KX880866 & KX880933 \\
\hline Ustilago maydis & AFTOL-ID 505 & & & $\begin{array}{l}\text { AFTOL } \\
\text { database }\end{array}$ & AY485636 & \\
\hline Vararia abortiphysa & CBS 630.81 & KR364005 & KR364133 & - & KR364266 & - \\
\hline $\begin{array}{l}\text { Wrightoporia } \\
\text { srilankensis }\end{array}$ & Dai 19667 & MN688692 & MN688685 & MW290318 & - & MW290326 \\
\hline Wrightoporia lenta & Dai 10462 & KJ513291 & KJ807082 & - & - & - \\
\hline $\begin{array}{l}\text { Wrightoporia } \\
\text { subavellanea }\end{array}$ & Dai 11488 & KJ513296 & KJ807086 & - & - & - \\
\hline Хerocomus sp. & HKAS52557 & KC215207 & KC215220 & KC215225 & KC215234 & KC215243 \\
\hline
\end{tabular}

Note: New sequences are in bold.

Maximum parsimony (MP) analysis was also applied to the combined ITS+nLSU+RPB1+RPB2+TEF1 dataset. Tree construction was performed in PAUP* version 4.0b10 (Swofford 2002). All characters were equally weighted and gaps were treated as missing data. Trees were inferred using the heuristic search option with TBR branch swapping and 1000 random sequence additions. Max-trees were set to 5000, branches of zero length were collapsed and all parsimonious trees were saved. Clade robustness was assessed using a bootstrap (BT) analysis with 1000 replicates (Felsenstein 1985). Descriptive tree statistics tree length (TL), consistency index (CI), retention index (RI), rescaled consistency index (RC), and homoplasy index (HI) were calculated for each maximum parsimonious tree (MPT) generated. Phylogenetic trees were visualized using Treeview (Page 1996).

Maximum likelihood (ML) and Bayesian inference (BI) analysis were applied to the combined dataset too. Substitution models suitable for each partition in the dataset were determined using Akaike Information Criterion (AIC) implemented in MrModeltest2.3 (Nylander 2004). The GTR $+\mathrm{I}+\mathrm{G}$ model was estimated as the best-fit evolution models for all partition in the combined dataset. BI was calculated with MrBayes 3.1.2 (Ronquist \& Huelsenbeck 2003) with GTR+I+G model of DNA substitution and an invgamma distribution rate variation across sites. Four Markov chains were run for 2 runs from random starting trees for 6 million generations of the combined dataset and sampled every 100 generations. The burn-in was set to discard the first $25 \%$ of the trees. 
A majority rule consensus tree of all remaining trees was calculated. ML tree was done applying raxmlGUI 1.2 (Stamatakis 2006, Silvestro \& Michalak 2012) with the model GTR + I + G and the option of auto FC (Pattengale et al. 2010) in BS (bootstrap) replicates. Branches that received bootstrap support values for MP and ML greater than or equal to $70 \%$ and BPP greater than or equal to 0.95 were considered as significantly supported.

\section{Divergence time estimation}

The BEAST 1.8.0 software package was used to estimate divergence times (Drummond \& Rambaut 2007). Internal calibration to determine the divergence time between Ascomycota and Basidiomycota, 582 Mya, with the 400-million-years-old fossil Paleopyrenomycites devonicus Taylor et al. was used in present study. A normal distribution was applied by setting the mean and the standard deviation to 582.5 and 50.15 (Taylor et al. 2004). Two fossils for comparison were used, i: Archaeomarasmius leggetti Hibbett et al., an agaricoid fruiting body preserved in 90 Ma Dominican amber (Hibbett et al. 1997) as representative of the minimum age of Agaricales, ii: Quatsinoporites cranhamii S.Y. Sm. et al., a poroid fruiting body from Apple Bay on Vancouver Island from $113 \mathrm{Ma}$ (Smith et al. 2004) as representative of the minimum age of Hymenochaetales. An XML file with BEAUTI v1.8.4 with a combined RPB1 and RPB2 alignment was constructed. For both partitions, the GTR model was chosen as the best substitution model by MrModelTest, and a relaxed lognormal model was employed for molecular clock analysis (Drummond \& Rambaut 2007). The tree prior was set to Yule speciation. For each analysis, two independent runs were conducted for 5000 million generations. Log files of the two runs were combined using LogCombiner by setting the first $10 \%$ of the logs as burn-ins and then analyzed in Tracer 1.5 (http://tree.bio.ed.ac.uk/software/figtree/tracer). The resulting trees were also combined, interpreted in TreeAnnotator, and viewed in FigTree 1.4.0.

\section{Results}

\section{Phylogenetic analysis with the combined dataset}

The combined dataset included sequences from 52 fungal collections representing 49 species. The dataset had an aligned length of 4587 characters, of which 1635 characters are constant, 568 are variable and parsimony-uninformative, and 2384 are parsimony-informative. MP analysis yielded one equally parsimonious trees $(\mathrm{TL}=16245, \mathrm{CI}=0.356, \mathrm{RI}=0.538, \mathrm{RC}=0.191, \mathrm{HI}=0.644)$. The best model for the combined dataset estimated and applied in the BI was GTR+I+G. BI resulted in a similar topology with an average standard deviation of split frequencies $=0.006471$ to MP and ML analysis, and thus only the BI tree was provided. The phylogenetic tree inferred from the combined dataset (Fig. 1) shows that the newly sequence specimen formed a distinct lineage within Russulales.

The resulting phylogenetic tree was overall consistent with the previous reports (Larsson 2007, Chen et al. 2016). The phylogenetic analyses based on the combined dataset produced a well-resolved phylogeny, and twelve major clades of Russulales were identified (Fig. 1). Terrestriporia alba formed a distinct lineage with strong support in the Russulales clade, and was close to Albatrellaceae Nuss (Fig. 1).

\section{Divergence of Terrestriporiaceae}

The alignment of the two datasets (RPB1 and RPB2) are 668 and $1137 \mathrm{bp}$ in length respectively, consisted of 40 taxa. Analyses calibrated by Paleopyrenomycites devonicus (Fig. 2), 582 Mya between Ascomycota and Basidiomycota estimate the divergence time of Hymenochaetales at 176.11 \pm 0.64 Mya (120.03-234.73 Mya, 95\% HPD) and the divergence time of Agaricales at $137.19 \pm 0.5$ Mya (98.66-177.98 Mya, 95\% HPD), that meet the minimum age of Hymenochaetales and Agaricales at 113 Mya and 90 Mya. The initial diversification between Terrestriporiaceae and Albatrellaceae at 124.68 \pm 0.39 Mya (91.47-159.17 Mya, 95\% HPD). The estimated divergence times for other nodes are summarized in Fig. 2. 


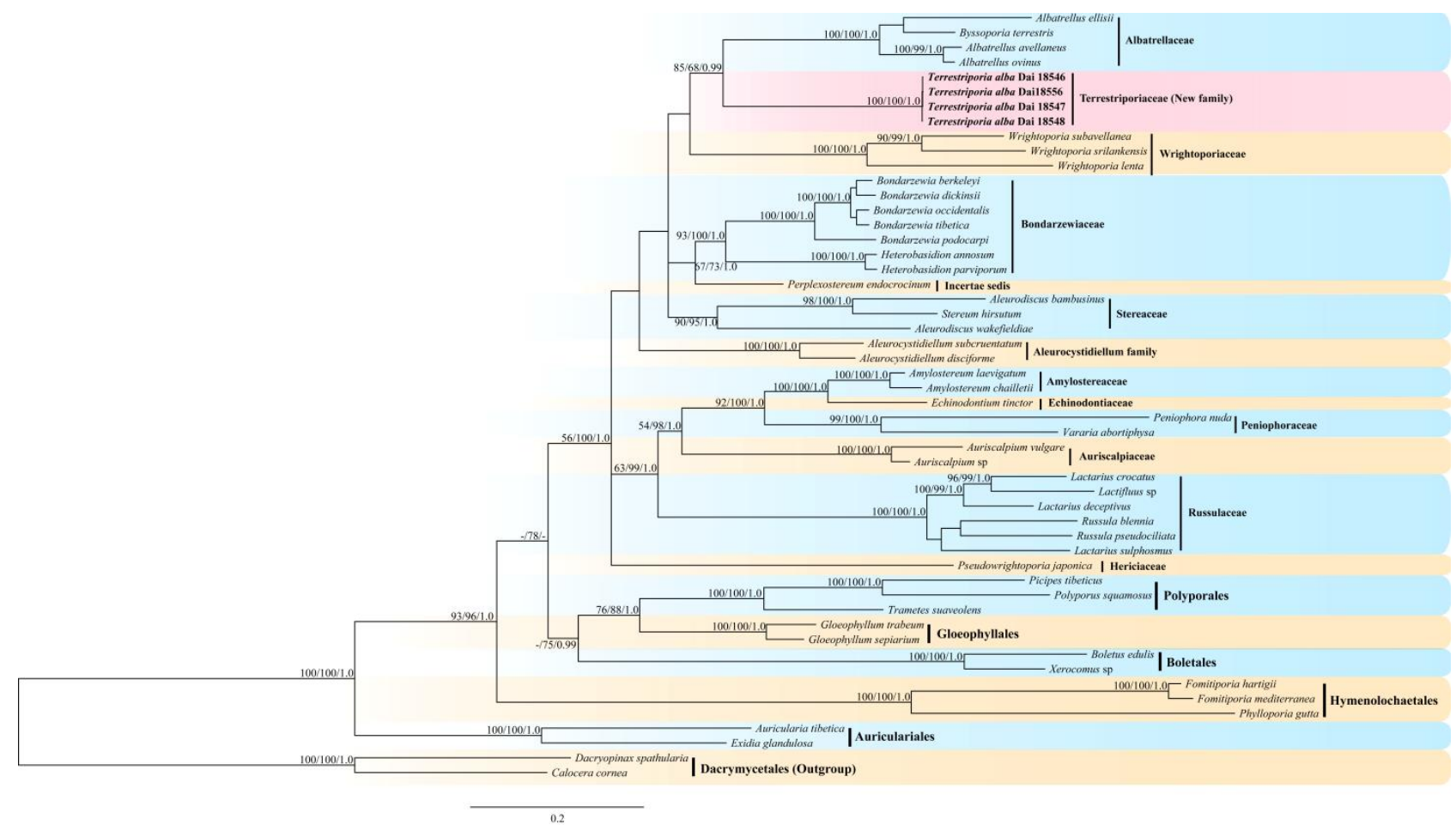

Figure 1 - BI tree illustrating the phylogeny of Terrestriporia alba, and related species in Agaricomycetes based on the combined ITS+nLSU+RPB1+RPB2+TEF1 dataset. Branches are labelled with maximum parsimony and maximum likelihood bootstrap proportions higher than $75 \%$ and Bayesian posterior probabilities more than 0.95 respectively.

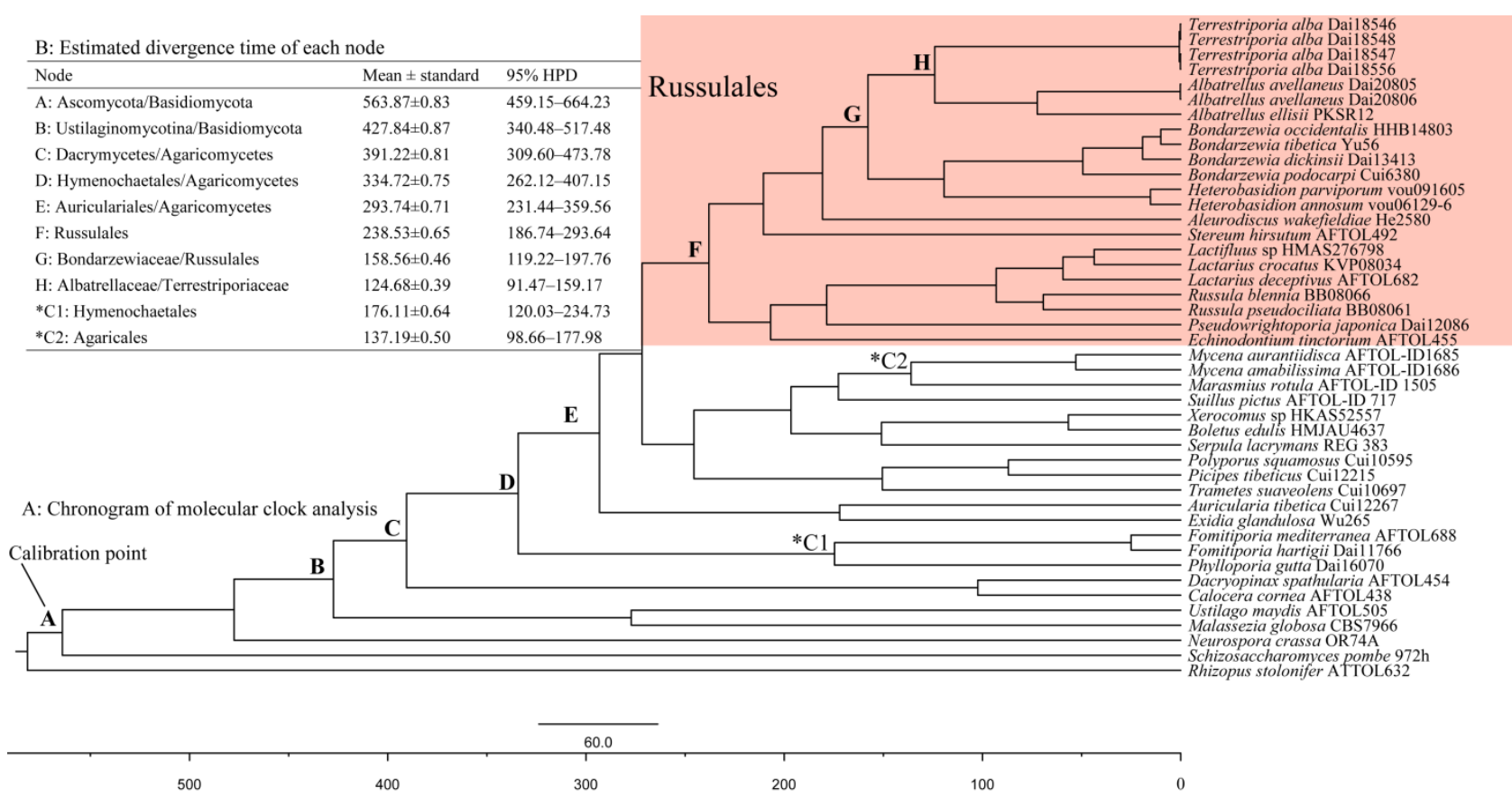

Figure 2-Chronogram and estimated divergence times of Terrestriporiaceae generated by molecular clock analysis using the RPB1 and RPB2 dataset. The chronogram was obtained using the Ascomycota-Basidiomycota divergence time of 582 Mya as the calibration point. The calibration point and objects of this study are marked in the chronogram. The geological time scale is in millions of years ago (Mya). 


\section{Taxonomy}

Terrestriporiaceae Y.C. Dai, B.K. Cui, F. Wu, Y. Yuan \& Jia J. Chen, fam. nov.

MycoBank number: MB 834539; Facesoffungi number: FoF 09499

Type genus - Terrestriporia Y.C. Dai, B.K. Cui, F. Wu, Y. Yuan \& Jia J. Chen

Habitat - grows on soil.

Rotting type - unknown.

Basidioma annual, resupinate, hymenophore poroid, hyphal structure monomitic, generative hyphae mostly simple septate, but occasionally having clamp connections, gloeoplerous hyphae present, basidiospores hyaline, thin-walled, smooth, amyloid.

Notes - The family Terrestriporiaceae is established to accommodate the genera Terrestriporia in the order Russulales based on its distinct lineage in the phylogenetic analysis. The combined phylogeny of five genes data (Fig. 1) demonstrates that Terrestriporiaceae is related to Albatrellaceae but shows no affinity to the other families of Russulales. The family Albatrellaceae includes mostly stipitate and mycorrhizal species. Hence a new family Terrestriporiaceae is established.

Terrestriporia Y.C. Dai, B.K. Cui, F. Wu, Y. Yuan \& Jia J. Chen, gen. nov.

MycoBank number: MB 834540; Facesoffungi number: FoF 09501

Etymology - Terrestriporia (Lat.): referring to the species in the genus growing on ground.

Type species - Terrestriporia alba Y.C. Dai, B.K. Cui, F. Wu \& Jia J. Chen, sp. nov.

Habitat - grows on soil.

Rotting type - unknown.

Basidioma annual, resupinate, hymenophore poroid and white, hyphal structure monomitic, generative hyphae mostly simple septate, but occasionally with clamp connections, gloeoplerous hyphae and gloeocystidioles present, basidiospores hyaline, thin-walled, smooth, amyloid, acyanophilous.

Terrestriporia alba Y.C. Dai, B.K. Cui, F. Wu, Y. Yuan \& Jia J. Chen, sp. nov.

Figs 3-5

MycoBank number: MB 834545; Facesoffungi number: FoF 09502

Diagnosis - Differs from other poroid species of Russulales by its annual and resupinate habit, a monomitic hyphal structure with both simple septa and clamp connections, the presence of both gloeoplerous hyphae and gloeocystidioles, ellipsoid, hyaline, thin-walled, smooth basidiospores.

Type - MALAYSIA, Kuala Lumpur, Forest Eco-Park, on ground of a slope with some fine roots in the soil, 14 April 2018, Dai 18548 (BJFC026837, holotype).

Etymology - Alba (Lat.): referring to the species having white pores.

Fruiting body - Basidioma annual, resupinate, inseparable from substrate, soft and without odour or taste when fresh, soft corky when dry. Pore surface white when fresh, becoming buff when dry; margin distinct, fimbriate, concolorous with pore surface, up to $3 \mathrm{~mm}$ wide, thinning out; pores round to angular, 2-3 per $\mathrm{mm}$; dissepiment thick, entire to slightly lacerate, cottony. Subiculum concolorous with pores, cottony to soft corky, up to $0.4 \mathrm{~mm}$ thick. Tubes concolorous with hymenophore, soft corky, up to $0.7 \mathrm{~mm}$ long.

Hyphal structure - Hyphal system monomitic; generative hyphae mostly simple septate, occasionally bearing clamp connections; all hyphae IKI-, CB-, frequently encrusted by fine crystals; tissues unchanged in $\mathrm{KOH}$.

Subiculum - Generative hyphae hyaline, thin-walled with a wide lumen, frequently branched and simple septate, rarely bearing clamp connections, mostly smooth, rarely bearing crystals, interwoven, 3.5-5 $\mu \mathrm{m}$ in diam.; gloeoplerous hyphae present, almost the same size as generative hyphae.

Tubes - Generative hyphae hyaline, thin-walled with a wide lumen, frequently branched and simple septate, occasionally bearing clamp connections, frequently bearing fine crystals, interwoven, 2.5-4.5 $\mu \mathrm{m}$ in diam; gloeoplerous hyphae present, almost the same size as generative hyphae; gloeocystidioles present, fusoid, 17-40 $\times 4-7 \mu \mathrm{m}$; fusoid cystidioles present, hyaline, thin-walled, 
almost the same size as gloeocystidioles; basidia clavate to barrel-shaped, bearing four sterigmata and a basal simple septum, 18-27 $\times 5-8 \mu \mathrm{m}$; basidioles in shape similar to basidia, but slightly smaller.

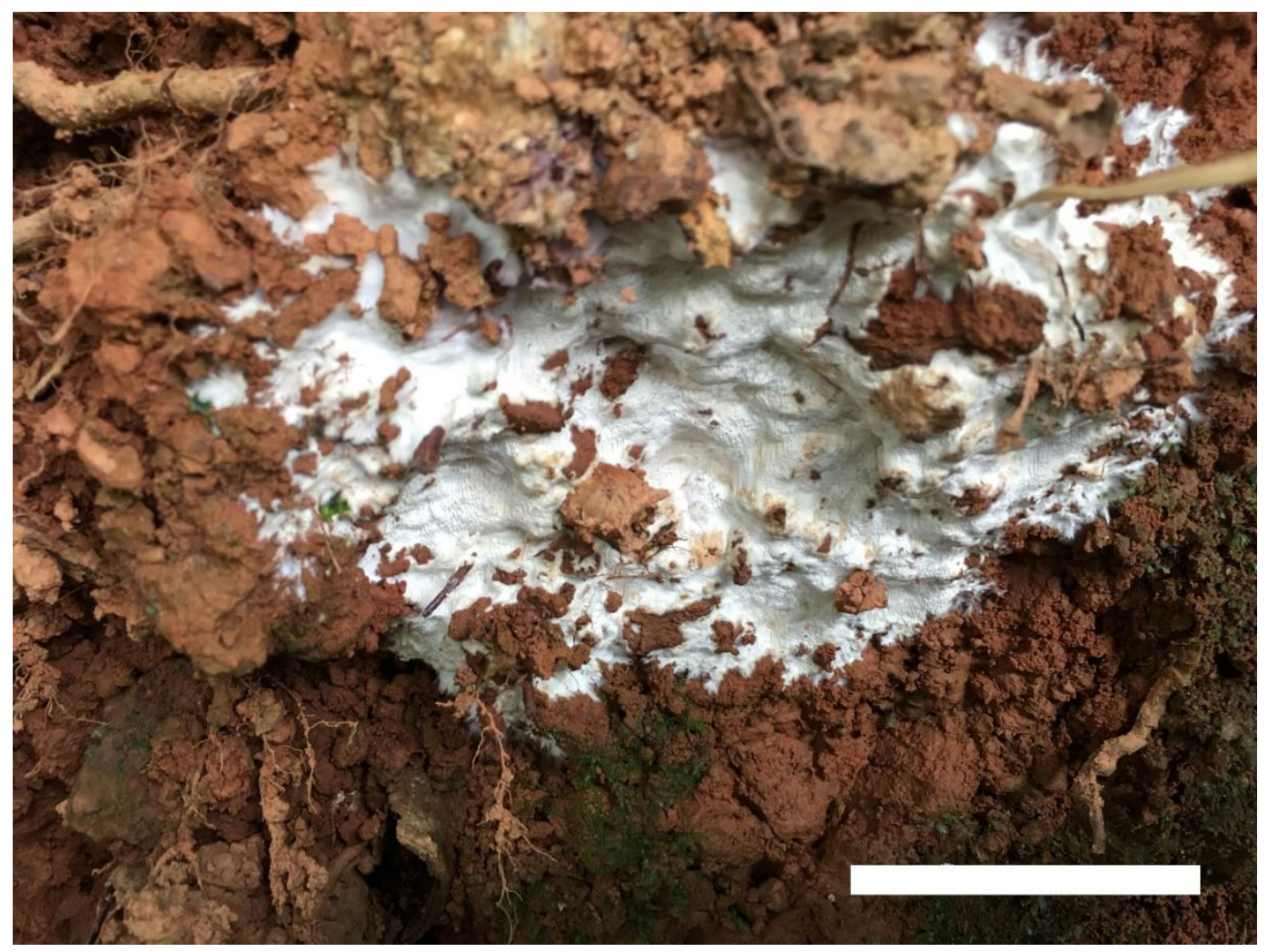

Figure 3 - Basidioma of Terrestriporia alba. Scale bar $=4 \mathrm{~cm}$ (Dai 18548, holotype).

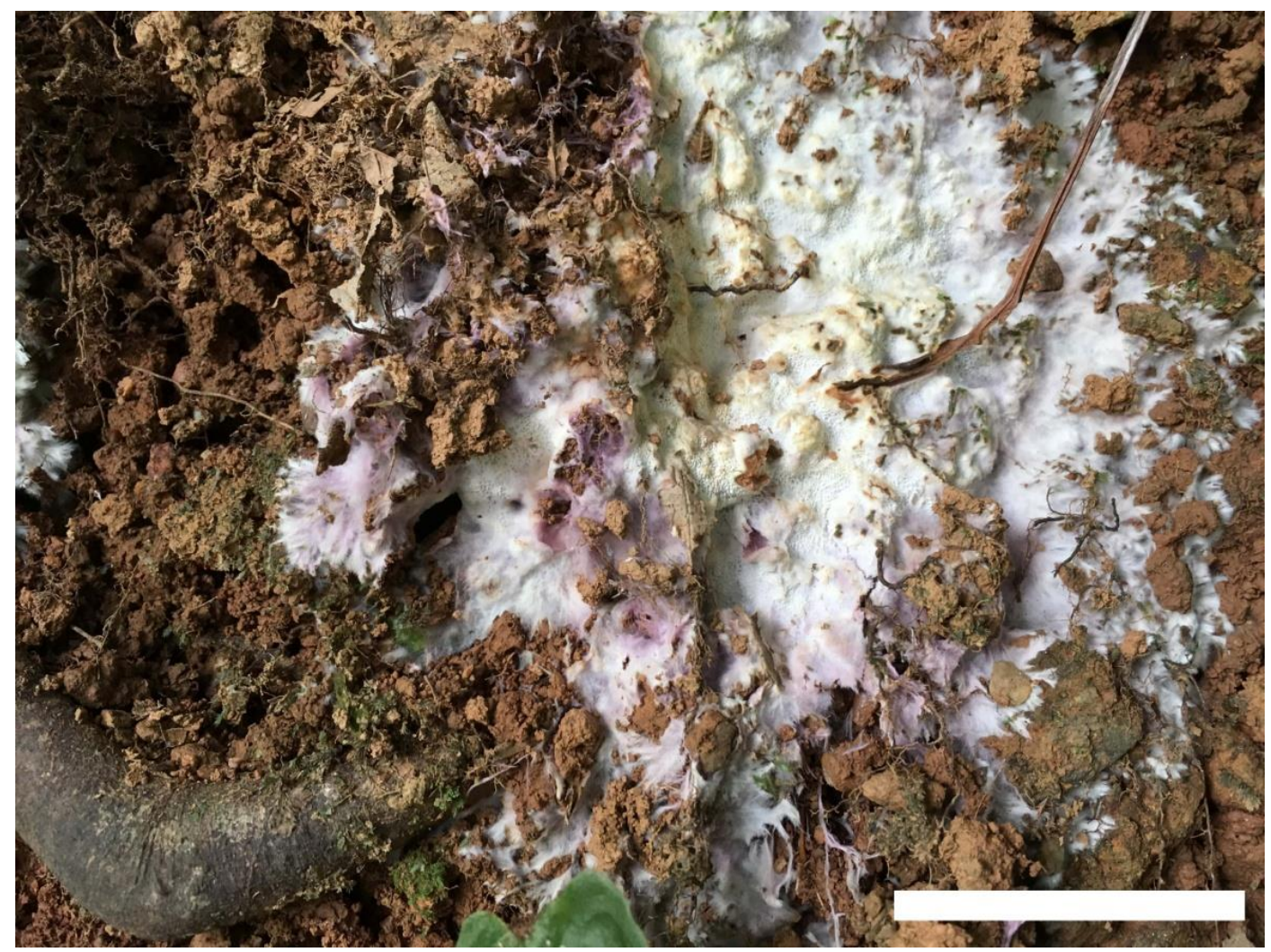

Figure 4 - Basidioma of Terrestriporia alba. Scale bar $=4 \mathrm{~cm}$ (Dai 18547, paratype). 
Spores - Basidiospores ellipsoid, hyaline, thin-walled, smooth, IKI+, CB-, (4.1-)4.2-6(-7.2) $\times(2.8-) 3-3.6(-3.8) \mu \mathrm{m}, \mathrm{L}=5.08 \mu \mathrm{m}, \mathrm{W}=3.11 \mu \mathrm{m}, \mathrm{Q}=1.5-1.69(\mathrm{n}=90 / 3)$.

Specimens examined (paratypes) - MALAYSIA, Kuala Lumpur, Forest Eco-Park, on ground of a slope with some fine roots in the soil, 14 April 2018, Dai 18546 (BJFC026835), Dai 18547 (BJFC026836) \& Dai 18556 (BJFC026845).
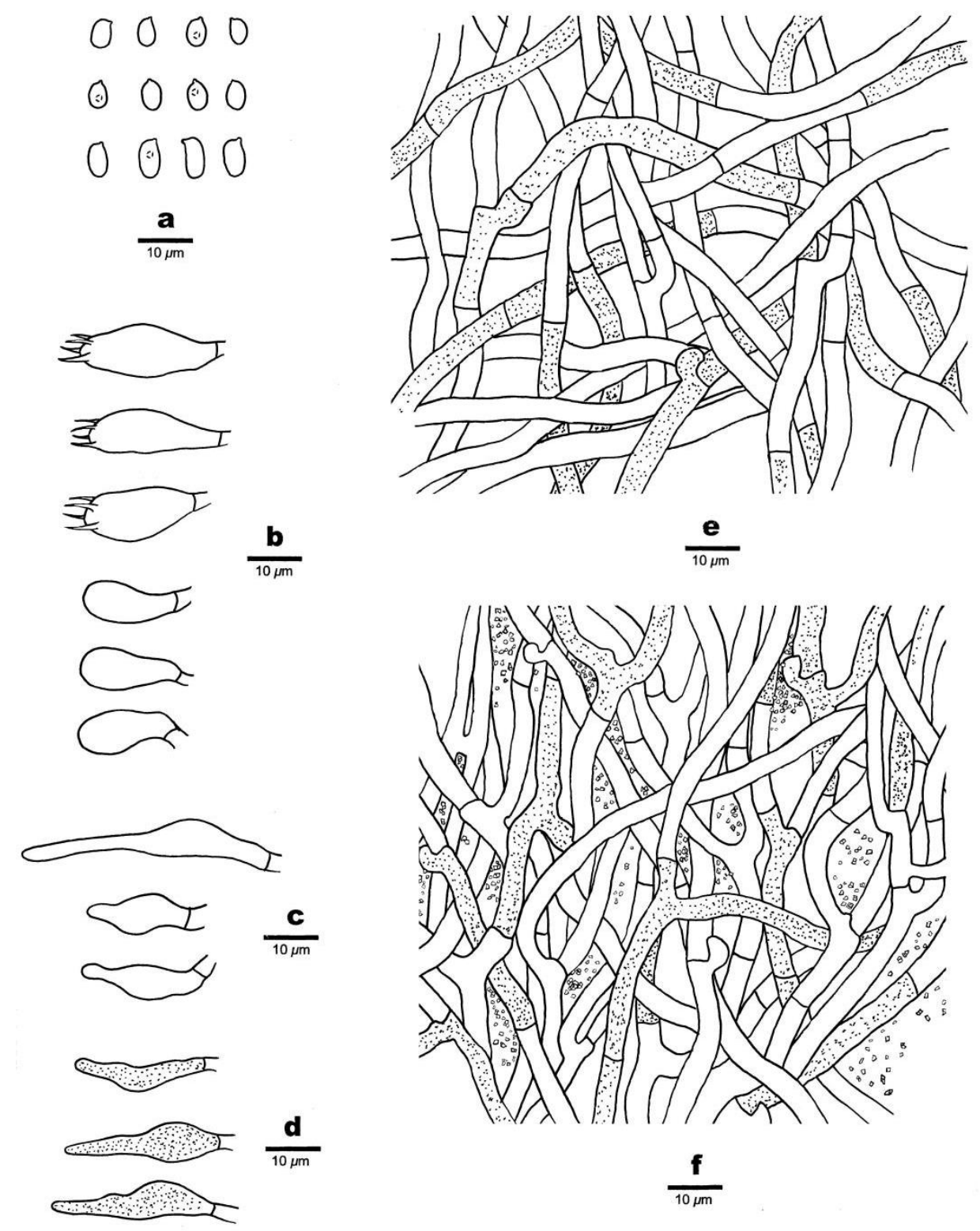

Figure 5 - Microscopic structures of Terrestriporia alba (drawn from the holotype). a Basidiospores. b Basidia and basidioles. c Cystidioles. d Gloeocystidioles. e Hyphae from subiculum. f Hyphae from trama.

\section{Discussion}

Morphologically, Terrestriporia alba is similar to Byssoporia terrestris (DC.) M.J. Larsen \& Zak by annual, resupinate basidioma with fimbriate margin, a monomitic hyphal structure with both simple septa and clamp connections, and growing on ground (Ryvarden \& Melo 2014). However, the latter species lacks gloeoplerous hyphae and gloeocystidioles, and its basidiospores are slightly thick-walled, negative in Melzer's reagent. In addition, Byssoporia M.J. Larsen \& Zak is closely related to Albatrellus Gray which is a stipitate genus belonging to Albatrellaceae (Fig. 1). 
Terrestriporia resembles Anomoporia Pouzar and Anomoloma Niemelä \& K.H. Larss. by sharing annual and resupinate basidioma, a monomitic hyphal structure, and hyaline, thin-walled, smooth and amyloid basidiospores (Ryvarden \& Melo 2014), but the latter two genera have clamp connections only, lack gloeoplerous hyphae and cystidioles, and belong to Amylocorticiales.

Terrestriporia alba occupies similar ecological habitat growing on ground with some fine roots in the soil as some species in Rhizochaete Gresl., Nakasone \& Rajchenb. and Sebacina Tul. \& C. Tul. (e.g. Rhizochaete radicata (Henn.) Gresl., Nakasone \& Rajchenb. and Sebacina epigaea (Berk. \& Broome) Bourdot \& Galzin), but the latter two genera have smooth or tuberculate hymenophores, and they belong to Sebacinales and Polyporales, respectively (Breitenbach \& Kränlin 1988, Greslebin et al. 2004).

Among species in Russulales, the DNA sequences of the ITS regions of Terrestriporia alba are more similar to Perplexostereum endocrocinum (Berk.) Ryvarden \& Tutka, but the latter has perennial, pileate and hard basidioma with smooth hymenophore, a dimitic hyphal structure with clamp connections only, distinctly ornamented basidiospores, and growing on wood of Juniperus (Ryvarden \& Tutka 2014). It is therefore both species have completely different morphology and ecology. In addition, the familial placement for Perplexostereum Ryvarden \& Tutka is still unresolved and it has been referred to incertae sedis.

Divergence times have been used in ranking taxa (especially in higher taxa ranking) in different fungal groups (Divakar et al. 2017, Hongsanan et al. 2017, Zhao et al. 2017, Zhang et al. 2019). The divergence time of Terrestriporiaceae is also estimated and its divergence time from Albatrellaceae is $124.68 \pm 0.39 \mathrm{Mya}$, which supports recent study of ranking a family with divergence time estimates (Zhao et al. 2017, Zhang et al. 2019).

\section{Acknowledgements}

We would like to express our deep thanks to Prof. Jian-Yun Zhuang (Beijing, China) helped us the Latin. The research is supported by the National Natural Science Foundation of China (Project No. 31870007).

\section{References}

Anonymous. 1969 - Flora of British fungi. Colour identification chart. Her Majesty's Stationery Office, London.

Breitenbach J, Kränlin F. 1988 - Fungi of Switzerland 2. Non-gilled fungi, Heterobasidiomycetes, Aphyllophorales, Gasteromycetes. Mykologia, Luzern, 1-412 pp.

Caboň M, Li GJ, Saba M, Kolař́k M et al. 2019 - Phylogenetic study documents different speciation mechanisms within the Russula globispora lineage in boreal and arctic environments of the Northern Hemisphere. IMA Fungus. 1(no. 5), 1-16.

Chen JJ, Cui BK, Dai YC. 2016 - Global diversity and molecular systematics of Wrightoporia s. 1. (Russulales, Basidiomycota). Persoonia 37, 21-36.

Chen JJ, Cui BK, Zhou LW, Korhonen K et al. 2015 - Phylogeny, divergence time estimation, and biogeography of the genus Heterobasidion (Basidiomycota, Russulales). Fungal Diversity 71, 185-200.

Divakar PK, Crespo A, Kraichak E, Leavitt S et al. 2017 - Using a temporal phylogenetic method to harmonize family- and genus-level classification in the largest clade of lichen-forming fungi. Fungal Diversity 84, 101-117.

Drummond AJ, Rambaut A. 2007 - BEAST: Bayesian evolutionary analysis by sampling trees. BMC Evolution Biology 7, 214-221.

Felsenstein J. 1985 - Confidence intervals on phylogenetics: an approach using bootstrap. Evolution 39, 783-791.

Greslebin A, Nakasone KK, Rajchenberg M. 2004 - Rhizochaete, a new genus of phanerochaetoid fungi. Mycologia 96, 260-271. 
Henkel TW, Aime MC, Miller SL. 2000 - Systematics of pleurotoid Russulaceae from Guyana and Japan, with notes on their ectomycorrhizal status. Mycologia 92, 1119-1132.

Herrera M, Montoya L, Bandala VM. 2018 - Two Lactarius species (subgenus Plinthogalus) in ectomycorrhizal association with tropical Quercus trees in eastern Mexico. Mycologia 110, 1033-1046.

Hibbett DS, Grimaldi D, Donoghue MJ. 1997 - Fossil mushrooms from Miocene and Cretaceous ambers and the evolution of homobasidiomycetes. American Journal of Botany 84, 981-991.

Hongsanan S, Maharachchikumbura SS, Hyde KD, Samarakoon MC et al. 2017 - An updated phylogeny of Sordariomycetes based on phylogenetic and molecular clock evidence. Fungal Diversity 84, 25-41.

Hyde KD, Norphanphoun C, Abreu VP, Bazzicalupo A et al. 2017 - Fungal diversity notes 603-708: taxonomic and phylogenetic notes on genera and species. Fungal Diversity 87, 1-235.

Kirk PM, Cannon PF, Minter DW, Stalpers JA. 2008 - Ainsworth and bisby's dictionary of the fungi. 10th ed. Wallingford, Oxon, UK: CAB International Press.

Larsson KH. 2007 - Re-thinking the classification of corticioid fungi. Mycological Research 111, 1040-1063.

Larsson KH, Larsson E, Koljalg U. 2004 - High phylogenetic diversity among corticioid Homobasidiomycetes. Mycological Research 108, 983-1002.

Leal-Dutra CA, Neves MA, Griffith GW, Reck MA et al. 2018 - Reclassification of Parapterulicium Corner (Pterulaceae, Agaricales), contributions to Lachnocladiaceae and Peniophoraceae (Russulales) and introduction of Baltazaria gen. nov. Mycokeys 37, 39-56.

Liu SL, Tian Y, Nie T, Thawthong A et al. 2017 - Updates on East Asian Asterostroma (Russulales, Basidiomycota): new species and new records from Thailand and China. Mycological Progress 16, 667-676.

Matheny PB, Liu YJ, Ammirati JF, Hall BD. 2002 - Using RPB1 sequences to improve phylogenetic inference among mushrooms (Inocybe, Agaricales). American Journal of Botany 89, 688-698.

Matheny PB. 2005 - Improving phylogenetic inference of mushrooms with RPB1 and RPB2 nucleotide sequences (Inocybe, Agaricales). Molecular Phylogenetic Evolution 35, 1-20.

Nylander J. 2004 - MrModeltest v2. Program distributed by the author. Uppsala: Evolutionary Biology Centre, Uppsala University.

Page RDM. 1996 - Treeview: application to display phylogenetic trees on personal computers. Computer Applications in the Biosciences 12, 357-358.

Pattengale ND, Alipour M, Bininda-Emonds ORP, Moret BME et al. 2010 - How many bootstrap replicates are necessary? Journal of Computational Biology 17, 337-354.

Petersen JH. 1996 - The Danish Mycological Society's colour-chart. Greve Foreningen til Svampekundskabens Fremme.

Rehner S. 2001 - Primers for Elongation Factor 1-a (EF1-a). http://ocid.nacse.org/research/deephyphae/EF1 primer.pdf

Ryvarden L, Melo I. 2014 - Poroid fungi of Europe. Synopsis Fungorum 31, 1-455.

Ryvarden L, Tutka S. 2014 - Perplexostereum Ryvarden \& Tutka nov. gen. Synopsis Fungorum 32, $72-75$.

Ronquist F, Huelsenbeck JP. 2003 - MRBAYES 3: bayesian phylogenetic inference under mixed models. Bioinformatics 19, 1572-1574.

Smith SY, Currah RS, Stockey RA. 2004 - Cretaceous and Eocene poroid hymenophores from Vancouver Island, British Columbia. Mycologia 96, 180-186.

Silvestro D, Michalak I. 2012 - raxmlGUI: a graphical front-end for RAxML. Organisms Diversity \& Evolution 12, 335-337.

Stamatakis A. 2006 - RAxML-VI-HPC: maximum likelihood-based phylogenetic analyses with thousands of taxa and mixed models. Bioinformatics 22, 2688-2690.

Swofford DL. 2002 - PAUP*: Phylogenetic analysis using parsimony (*and other methods). Version 4.0b10. Massachusetts: Sinauer Associates. 
Song J, Cui BK. 2017 - Phylogeny, divergence time and historical biogeography of Laetiporus (Basidiomycota, Polyporales). BMC Evolutionary Biology 17, 102.

Taylor TN, Hass H, Kerp H, Krings M et al. 2004 - Perithecial ascomycetes from the 400 million year old Rhynie chert: an example of ancestral polymorphism. Mycologia 96, 1403-1419.

Thompson JD, Gibson TJ, Plewniak F, Jeanmougin F et al. 1997 - The Clustal_X windows interface: fexible strategies for multiple sequence alignment aided by quality analysis tools. Nucleic Acids Research 25, 4876-4882.

Vidal JM, Alvarado P, Loizides M, Konstantinidis G et al. 2019 - A phylogenetic and taxonomic revision of sequestrate Russulaceae in Mediterranean and temperate Europe. Persoonia 42, $127-185$.

Vilgalys R, Hester M. 1990 - Rapid genetic identification and mapping of enzymatically amplified ribosomal DNA from several Cryptococcus species. Journal of Bacteriology 172, 4238-4246.

Vizzini1 A, Angelini C, Losi C, Ercole E. 2018 - Diversity of polypores in the Dominican Republic: Pseudowrightoporia dominicana sp. nov. (Hericiaceae, Russulales). Mycokeys 34, 35-45.

Wang XH. 2018 - Fungal Biodiversity Profiles 71-80. Cryptogamie Mycologie 39, 419-445.

White TJ, Bruns T, Lee S, Taylor J. 1990 - Amplification and direct sequencing of fungal ribosomal RNA genes for phylogenetics. In: Innis, M.A., Gefand, D.H., Sninsky, J.J. \& White, J.T. (Eds.) PCR Protocols: a guide to methods and applications (eds.). Academic Press, San Diego, pp. $315-322$.

Zhao RL, Li GJ, Sánchez-Ramírez S, Stata M et al. 2017 - A six-gene phylogenetic overview of Basidiomycota and allied phyla with estimated divergence times of higher taxa and a phyloproteomics perspective. Fungal Diversity 84, 43-74.

Zhang SN, Hyde KD, Jones EBG, Jeewon R et al. 2019 - Striatiguttulaceae, a new pleosporalean family to accommodate Longicorpus and Striatiguttula gen. nov. from palms. Mycokeys 49, 99-129. 